\title{
La ciudadanía como conexión política entre las identidades en el Perú
}

\author{
The citizenship like a political conexion between identities in Perú
}

Ernesto W. Llanos ${ }^{1}$

\begin{abstract}
Resumen
El objetivo del presente estudio fue abordar la complejidad de la identidad peruana desde varios ángulos, haciendo uso de distintos instrumentos teóricos para resignificar sus límites difusos y espacios entrecruzados bajo un método hermenéutico. Uno de los caminos para afrontar esta problemática es considerar el potencial de la ciudadanía para constituir una identidad política que permita la interrelación e interconexión entre la variedad de grupos sociales y culturales que conviven y se influencian mutuamente en la sociedad peruana. Para ello, se analizó algunas manifestaciones culturales como la música, las artes audiovisuales y la cocina, encontrando una serie de identidades y modelos de identificación que reflejan estereotipos presentes en nuestro contexto y ante los cuales se plantea un análisis crítico.
\end{abstract}

Palabras clave: ciudadanía; cultura; identidades; Perú; política; sociedad.

\begin{abstract}
The aim of this paper it was address the complexity of the Peruvian identity from various angles and using various theoretical tools to resignify its fuzzy boundaries and intersecting spaces under a hermeneutical method. One of the ways to address this problem is to consider the potential of citizens to form a political identity that allows interaction and interconnection among the variety of social and cultural groups coexist and influence each other in Peruvian society. To do this, we look at some cultural events such as music, visual arts and cuisine, finding a series of identities and identification models that reflect stereotypes in our context and in which a critical analysis arises.
\end{abstract}

Keywords: citizenship; culture; identities; Peru; politic; society.

\section{Introducción}

Esta investigación abordó el problema de la identidad que se muestra en la cultura, a fin de vislumbrar sus repercusiones sociales y políticas. El alcance de la investigación es explicativo, en el sentido que busca replantear a la ciudadanía en torno a una identidad política que, integre y posibilite la interacción de los diferentes grupos sociales y culturales del país. Por tal motivo, el principal objetivo es contrastar algunos conceptos, perspectivas y enfoques pertinentes, desde diferentes disciplinas y referencias bibliográficas fundamentales. La filosofía hermenéutica por un lado y por otro, el texto de Castoriadis (1997) " $E l$ Avance de la insignificancia”; del ámbito de la sociología el trabajo de Portocarrero y Komadina (2001) "Modelos de identidad y sentidos de pertenencia en Perú y Bolivia”; y de la politología, Sartori (1988) y su obra la "Teoría de la democracia", para tratar de construir un discurso analítico, sintético, crítico y hermenéutico, a fin de crear interconexiones entre las problemáticas culturales, sociales y políticas.

\section{Materiales y métodos}

Se estudió la problemática de las identidades y su relación con la ciudadanía en el Perú. La metodología que se utilizó estuvo basada en un enfoque cualitativo, ya que buscó comprender la realidad a partir de las interpretaciones de diferentes manifestaciones culturales desde la filosofía, la sociología y las ciencias políticas. El diseño de la investigación es interpretativo, porque se usó un enfoque multidimensional para ensayar una ordenación y estereotipos de la problemática social y cultural de la diversidad peruana, a partir de los imaginarios captados en las manifestaciones populares. Para ello, se usaron algunas categorías de la filosofía y de la sociología, a fin de deducir probabilidades.

\section{Resultados y discusión}

\section{Identidad e identificación}

\section{Dinámicas y niveles de identificación complejos}

Podemos establecer tres niveles de identificación que se entrecruzan en el mundo interior de las personas, estas son: en primer lugar, el nivel personal o individual, campo en que se desarrolla la identidad psicológica. El segundo, la identificación microsocial o comunitaria, estudiada por diversas disciplinas como la psicología, la antropología, la sociología, entre otras, está desarrollada por las diferentes interacciones sociales de manera simultánea, que se expresan dependiendo de los contextos o espacios sociales 
en los que nos desenvolvemos, como la familia, el barrio, el centro de estudios, el trabajo, las agrupaciones políticas y los diferentes círculos sociales. Por último, el nivel de identificación macrosocial, político-social, políticonacional o ciudadanía política, que puede ser analizado tanto desde las ciencias sociales, la sociología política, filosofía política y otras disciplinas. Aquí se manifiestan las identidades nacionales y los procesos de identificación política de los ciudadanos de un Estado.

Respecto a las identidades nacionales, no podemos limitar su comprensión a la teórica clásica de naciónestado moderno, desde la cual se identificaba directamente la identidad cultural con la nacional, en la conjugación "una lengua, una cultura, una nación". Esta concepción es imposible en nuestra época debido a las complejas y heterogéneas culturas que forman las sociedades latinoamericanas como el Perú, que asimismo, participan de los procesos migratorios, producto del fenómeno de la globalización a nivel mundial.

En relación a lo mencionado, tenemos que distinguir entre las identidades culturales y nacionales, pues, hay grupos culturales que forman parte de una o de varias identidades. Por ejemplo, en Bolivia y el Perú, conviven un conjunto diverso de etnias culturales como los quechuas y los aymara, más allá de los límites de estos dos estados modernos.

Este estudio buscó proponer que la identidad ciudadana puede servir como instrumento de cohesión, unión e integración intercultural para una articulación política que permita la viabilidad de un proyecto nacional (incluso transnacional) y el funcionamiento de un estado frente a las nuevas dinámicas y cambios socioculturales alrededor del globo.

\section{Redefinición integrada del concepto de identidad e identificación}

La comprensión de los niveles de complejidad sobre la identificación nos lleva a preguntarnos por la complejidad de las identidades y los aspectos que subyacen a ellas. Partiendo de la lógica, la matemática, la filosofía del lenguaje y la analítica; tomando como centro la teoría de conjuntos, se abordó varios conceptos que permitirán tener una idea más integral de la identidad.

El principio lógico de no contradicción puede resumirse en $a=a$, e interpretarse en que, algo es igual e idéntico a sí mismo y diferente a otros seres u objetos. Este principio puede ser trasladado tanto a la psicología como a la sociología, pues la identidad personal o social, permite diferenciar personas y comunidades unas de otras.

Otro concepto que se puede integrar, es el sentido de pertenencia, pues la identidad también se define por un sentido de pertenencia a un grupo (Vargas, s.f.). Los elementos de un conjunto pueden ser definidos de dos formas: la primera, por extensión, es decir, por la enumeración de los elementos que lo comprenden, por ejemplo, el conjunto "peruanos" estaría comprendido por todas aquellas personas que han nacido en el territorio peruano o que hayan sido inscritos por sus padres como ciudadanos peruanos en otros países. En teoría, se podría revisar una base de datos que consigne los nombres de todas las partidas de nacimiento y restándole todas las actas de defunción. Y la segunda, definir un conjunto por comprensión, a través de la descripción de las características que comparten todos los elementos, como "x/x es una vocal del abecedario", en este caso, sabemos que la respuesta por extensión es $(\mathrm{a}, \mathrm{e}, \mathrm{i}, \mathrm{o}, \mathrm{u})$; como vemos, la definición por comprensión es un concepto abstracto, un concepto de relación y pertenencia, una identificación simbólica que determina una relación social intersubjetiva como un grupo de ideas, creencias, costumbres, historia, etc., las que permiten la identificación de un grupo de sujetos y la diferenciación con otros. Esto nos lleva a cuestionar si alguna vez se ha elaborado o construido un discurso que permita la definición por comprensión del conjunto "peruanos" o si es posible realizarlo.

La dificultad de integrar un conjunto conformado por grupos sociales diversos, algunos de los cuales tienen subconjuntos y se encuentran intersectados entre sí, es la falta de una verdadera pertenencia o identificación ciudadana política nacional, pues muchos peruanos sienten una mayor pertenencia a una familia, etnia o región que a la nación; esto se evidencia en los conflictos sociales, en la discriminación, en la falta de respeto ante la ley y en el cuidado del patrimonio cultural y natural. Por estas razones la tarea de relacionar todos estos conjuntos sociales en un gran conjunto universal es un verdadero reto social y político.

Para lograr el objetivo, se debe considerar el concepto de identidad de manera más flexible e integral, como una relación simbólica y dinámica que permite, a partir de distintos imaginarios, conformar una comunidad cultural; en ese sentido, tomaremos algunas ideas del texto "En el crisol de las apariencias" de Maffesoli (2007). Según el autor, la identidad es concebida como producto de la modernidad, es una lógica basada en la unidad individual estática, que en la actualidad ha perdido fuerza y se está diluyendo a causa de los vertiginosos cambios de las últimas décadas, donde todo se ha vuelto diverso y múltiple. Otro efecto de esa disolución de la individualidad moderna es que influye en el proceso dinámico de la identificación y las múltiples pertenencias a los diversos grupos sociales y culturales. Tanto en el mundo como en el Perú, se altera la formación de relaciones sociales, identidades e interacciones por el concurso de múltiples facetas, roles y máscaras que constituyen el ser complejo en un continuum.

Maffesoli (2007) presentó a un individuo perdido en medio de una serie de identidades, producto de la posmodernidad y de los diferentes contextos donde se desenvuelven las personas. Por esta razón, él prefiere hablar del proceso de identificación y no usar el término identidad, que considera estático, pues la identidad es, finalmente, una construcción en constante cambio, enfatizada por las diferentes comunidades de las cuales participamos, incluyendo las virtuales. 
En otras palabras, "Es esta multiplicidad del yo lo que permite comprender la irrupción del afecto, la importancia de las emociones, las lógicas diferentes que lo animan, ajeno a todo esto, al recorrido rectilíneo y continuo que se le acredita, por principio y a priori, al individuo moderno"(Maffesoli, 2007), que ha sido diluido en la llamada posmodernidad.

\section{Intermedios, espacios y campos interculturales $y$ transculturales}

La complejidad de la sociedad peruana se debe en parte a la intersección de ciertas tradiciones culturales y de distintas "lógicas", "racionalidades", formas de pensar, cosmovisiones, imaginarios, discursos, entre otros, que posteriormente llamaremos campos y espacios simbólicos o culturales.

De un lado, persisten formas de pensar y actuar que pertenecen a las sociedades tradicionales o premodernas, como la moralidad, ciertos elementos comunitarios, una visión comercial regida por la negociación, una fuerte influencia de ideas y creencias de origen místico y religioso, entre otras muchas manifestaciones visibles en la vida cotidiana; simultáneamente, conviven los imaginarios simbólicos o cosmovisiones correspondientes a las sociedades modernas que se manifiestan por medio de los procesos de individualización, las formas económicas de carácter capitalista, el uso de la razón instrumental, etc., las mismas que forman parte de las relaciones sociales donde interactuamos.

De otro lado, con las dos formas de pensamiento anteriormente descritas, conviven algunas ideas y comportamientos calificados de posmodernos, propios de sociedades posindustriales, entre los cuales se puede percibir la conciencia de la influencia de la economía y la política internacional en la realidad nacional, el incremento del hedonismo y el hiperconsumo en algunos sectores sociales, el poder de los medios de comunicación, incluyendo Internet, la revaloración de los saberes tradicionales y más. Todo esto, deviene como resultado de los cambios acontecidos desde las últimas décadas del siglo XX y como crítica a la modernidad y sus consecuencias.

Como ejemplo de este traslape, en primer lugar, se tiene los campos o formas vinculadas a la tradición de las culturas precolombinas, algunas de ellas en estado casi puro, especialmente, las comunidades de la sierra y de la selva, alejadas de la civilización occidental, que han sobrevivido a los procesos históricos de la dominación española y la República. En segundo lugar, los diversos campos del pensamiento moderno, se encontró imaginarios que tienen su raíz en la llegada de la cultura occidental que introdujo cambios irreversibles: las fusiones culturales como el caso de los sincretismos religiosos (entre el catolicismo y la religiosidad precolombina), la institucionalización política y social de la colonia, proveniente de la península ibérica. Esta confluencia cristalizó en una cultura amalgamada, donde perviven elementos premodernos y modernos, como el catolicismo y el capitalismo. Con todo, este proceso no ha concluido, sino que la imposición de occidente desde el siglo XVI continúa, aunque bajo nuevas formas de dominación. En tercer lugar, los campos de pensamiento posmoderno asociados al actual consumismo poscapitalista, el cual está influenciado por dos poderes: las políticas económicas neoliberales implantadas desde los años noventa, impuestas por organismos internacionales como el Banco Mundial y el Fondo Monetario Internacional y las constantes innovaciones tecnológicas y los medios de comunicación que movilizan el comportamiento inmediatista, individualista, superficial, indiferente y hedonista, orientado a la acumulación de bienes materiales como símbolo de éxito.

Los tres campos descritos no son los únicos, pues existen una serie de espacios intermedios que permiten el paso de una "lógica" o "racionalidad" a otra, dependiendo del contexto. Estos espacios son tránsitos culturales, como el paso de lo formal a lo informal, el paso de la oferta y la demanda a la negociación, el paso de lo legal a lo ilegal. Algunos ejemplos de estos espacios intermedios, son los ámbitos de: lo interlegal, translegal, interformal y transformal. Vamos a graficarlo para que sea más claro. En su análisis etnográfico del acceso ilegal a la telefonía celular. Mujica (s.f) explicó la interrelación de los mercados legal e ilegal o informal y cómo la empresa de telecomunicaciones "legaliza" de manera informal los equipos robados, fortaleciendo el "mercado negro" y facilitando el acceso irregular a él. De esta forma, el celular es un híbrido de lo ilegal y lo legal, una fusión de mercados y de intereses, donde "todos ganan".

¿Cómo pasamos de un campo de pensamiento a otro, a través de los espacios intermedios? A veces, son espacios físicos como los mercados, galerías y zonas de ventas ambulantes, etc. donde podemos negociar o regatear los precios, somos los caseros que reciben un regalito ("la yapa") a diferencia de los centros comerciales, tiendas por departamentos, supermercados, etc. negocios y corporaciones, a veces de origen internacional, donde los precios están preestablecidos por las leyes del libre mercado.

Otras veces, el paso a estas ambiguas dimensiones son más sutiles, representado por frases como "¿cómo es?", “¿cómo arreglamos?”, que son las llaves o códigos sociales de acceso a lo ilegal pasando por lo interlegal o translegal o, también, para imponer jerarquías sociales de poder, tal como sucede con las expresiones "no seas igualado" o “¿sabes con quién estás hablando?”, que veremos después con mayor profundidad. En síntesis, el problema refiere al paso de la igualdad entre individuos iguales a sujetos jerarquizados de manera tradicional.

Se debe aclarar que, sin importar nuestra identidad cultural o las diferentes identificaciones que constituyen, un buen grupo de peruanos e incluso de latinoamericanos y tal vez cualquier otro grupo a nivel mundial, se pasa por espacios intermedios donde se cruzan los discursos o sistemas, cuyos límites son difusos. 


\section{Modelos de identificación}

Desde la segunda mitad de los años noventa, en los medios de comunicacióndel Perú, se observa, hasta el día de hoy, la aparición en aumento de modelos de identificación de la cultura popular mediatizada, combinando elementos extraídos de los estereotipos sociales andinos, amazónicos, en general migrantes y de la llamada cultura descrita como mestiza, chola y criolla, presentes en novelas, series y comerciales televisivos que se usan como estrategias de comercialización de los productos peruanos, con la consiguiente "valoración" de la cultura. Es el caso de las campañas de Inca Kola, de "compre productos peruanos", de cambio de imagen del Pisco peruano, y un sin número de ejemplos más.

El interés sobre los modelos de identificación también se expresa en otras esferas del conocimiento como las ciencias sociales; aquí se encontró estudios realizados con mayor profundidad y continuidad desde fines de los setenta, sobre la migración y la informalidad, y sus efectos en las ciudades, "la cultura chicha", la propuesta de la cholificación o lo cholo como el resultado del mestizaje social y cultural. Estos nuevos modelos de identificación constituyen una especie de fusión o intersección donde tiene lugar la formación de nuevas identidades, que no reemplazan a las anteriores sino que conviven con otras (identidad aristocrática, criolla, andina, afro y otras intermedias y puras, como el caso de algunas comunidades de la selva). Asimismo, estos modelos de identificación tienen otros campos de expresión y representación de la identidad, a través de las artes plásticas y las visuales, así como la música, la cocina, entre otros.

En líneas generales, hablar de los modelos de identificación como paradigmas que permite la generación de nuevas identidades, las que a su vez reflejan imágenes que dinamizan enriqueciendo y cuestionando los discursos que subyacen a dichos modelos de identificación. Esta dialéctica es imprescindible en nuestro contexto, toda vez que los medios de comunicación instrumentalizan sin conciencia moral esta relación. “(...) lejos de vivir una utopía, las imágenes en movimiento que vemos en la mayor parte del mundo no dan testimonio de felicidad, sino de la consolidación de la matriz cultural del entretenimiento y del ocio" (Protzel, 2009). Los medios de comunicación serían un espejo donde se reflejan ciertos aspectos culturales estereotipados a la orden de los fines del sistema de entretenimiento comercial. Tanto la publicidad, un sector del cine y la televisión utilizan modelos de identificación estereotipados, simplistas y caricaturescos para captar al público al que apuntan, sin importar que refuercen prejuicios, en tanto cumplan los objetivos comerciales. A continuación presentamos algunos modelos de identificación utilizados en medios de comunicación:

Aristócrata-pituco. Dominante, elitista, hedonista, despreocupado, excluyente. Propio de aquellos que encumbran su mundo jerarquizado, dueños de una gran corporación, imponen autoridad de herencia colonial- gamonal y viven en medio de lujos. Modelo dominado por la "lógica" del capitalismo del libre mercado y el hiperconsumo. Representado en los medios, utilizando individuos con rasgos físicos "europeos". En su interior, puede verse una clara división generacional: un gran conservadurismo por parte de los mayores y un estilo de vida desmedido en los jóvenes, producto del vacío y tedio de la vida contemporánea.

Una representación importante de este modelo se observa en la película "Dioses” de Josué Méndez, en la serie "Esta sociedad", y también en las telenovelas peruanas, aunque en las décadas haya perdido protagonismo.

Criollo-pendejo. Cuando se habla del criollo producto de la sociedad colonial debemos hacer una aclaración, en especial, debido a los cambios acaecidos en la etapa republicana, ya que se puede hablar de dos tipos de criollo: el aristócrata con poder o con apellido que comparte un estilo de vida acomodado y que ha sido descrito en el modelo anterior; y el criollo de clase media que ocupa trabajos de mando medio, cuyo carácter risueño tipifica al "vivo" o gran oportunista, que podemos relacionar con letras del cancionero criollo del siglo $\mathrm{XX}$, como por ejemplo: "Vacas y gallinas irán por las calles dando leche y huevos a más y mejor... gracias a Mandraque en estos cinco años vueltas de campanas dará la nación... Haremos casas de ochenta pisos, ómnibus nuevos más de cien mil... y las corvinas sobre las olas nadarán fritas con su limón".

Es un personaje que tiene contacto simultáneo con los sectores más poderosos y las clases más populares, que busca ascender socialmente al mundo aristocrático tratando de encontrar el momento oportuno, en el colegio, la universidad, el trabajo, etc., para acercarse lo suficiente e introducirse a las esferas de poder económico aristocrático. Su estereotipo físico es variado, puede ser blanco o mestizo. Es más flexible para pasar de un campo simbólico a otro si le es conveniente.

El mundo típico donde se desenvuelve este "criollo" es el barrio de clase media, representados en programas cómicos o en series como "Mil oficios" o "Así es la vida", "Al fondo hay sitio", encarnado normalmente por el actor cómico Adolfo Chuiman y su entorno de ficción constituye una típica referencia. El mundo "criollo" también se encuentra presente en personajes publicitarios, principalmente en algunos anuncios de cerveza.

Cholo-Chicha. Emprendedor, ingenioso, mestizo, migrante o hijo de migrantes, que mantiene sus tradiciones y ha aprendido a adaptarse a la ciudad y la ha trasformado e incluso la ha dominado, la hecho suya; pasó de ser invasor a protagonista de la ciudad, creando nuevos espacios, saliendo adelante con el esfuerzo comunitario, creando su propio trabajo, buscando el desarrollo y el progreso a través de la reformulación de su modo de pensar, tiene su propia dinámica comercial basada en relaciones de parentesco y con una lógica de negociación. Es el sujeto de estudio y el 
nuevo protagonista en los medios de comunicación, que no viene solo sino rodeado de un mundo emergente que ha pasado por procesos de cambios y es aceptado, en parte, por formar un nuevo y gran mercado de consumo popular y por constituirse como parte importante de un nuevo sector comercial y económico. Este modelo de identificación en los últimos años se ha convertido en tema central de ciertas propuestas artísticas que tratan de rescatar en la estética chicha, los elementos urbanos como anuncios de fiestas, transporte y vivienda, entre otros, en medio de un juego de colores y formas.

El cholo y su mundo chicha aparecieron con fuerza en la música de los ochenta y de manera profusa, en las telenovelas de los noventa como "Los de arriba y los de Abajo", programas cómicos como "Los cómicos Ambulantes", los talk show; y en los últimos años, series televisivas de corte biográfico, que tienen como protagonistas y modelos a los cantantes folkclóricos -como el caso de Dina Páucar o Chacalón-, quienes se han convertido en iconos del éxito y esfuerzo emergente y por eso, simbolizan la imagen de una marcas para atraer a un gran mercado popular, a veces, incluyendo el uso del quechua y el aymara.

Otro fenómeno social, asociado a lo anterior, es el gran boom de la cumbia, con mayor fuerza que el fenómeno de la chicha de los ochenta y la tecnocumbia de fines de los noventa e inicios del siglo XXI, pues ha trascendido a nivel nacional, creando no solo programas sino radios que trasmiten exclusivamente esta música de gran difusión y espacios televisivos para el mismo fin.

Andino-tradicional. Trabajador, religioso, tradicional, no puede desligarse del modelo anterior con el que está muy relacionado, pues la raíz cultural del cholo de la ciudad es el mundo andino del campo que mantiene costumbres $\mathrm{y}$ formas de pensamiento anteriores a la colonia. Ha sido postergado por el estado pero está produciendo sus propios cambios, busca cultivar el campo utilizando sus conocimientos heredados e implementándolos con otras tecnologías, así como potenciar sus conocimientos sobre su medio ambiente para una mejor producción. Durante varios siglos, ha sido estigmatizado como víctima mediante las imágenes peyorativas de serrano, indio, campesino, ignorante, e idealizado en las representaciones del arte y la literatura indigenista. Sin embargo, ha empezado a cambiar en algunos sectores con la revaloración de la tradición precolombina y el pensamiento ancestral. Su diversidad cultural está siendo aprovechada por el arte y la textilería, la agroindustria y las técnicas de regadío, el turismo y la gastronomía.

Afro-Negro-Zambo. Este modelo guarda relación con la comunidad de origen africano que llegó durante la colonia y su proceso de mestizaje. Su estereotipo suele ser limitado, pues los representantes son reducidos a tener un carácter alegre, con gran habilidad para los deportes y las artes, en especial para la música y la danza. Sin embargo, el aporte de la comunidad afroperuana es mucho más amplio, pero, a veces, es nublado por características negativas del estereotipo que lamentablemente fomentan la exclusión y la discriminación, como las supuestas, falta de inteligencia o de relación con actividades criminales. Esto último se refleja claramente en el personaje de Jorge Benavides, "El Negro Mama", quien ha sido transformado, en relación a su inicial actividad de estafador, presentándolo en los recientes capítulos como doctor, o ingeniero, debido a las constantes críticas por discriminación racial. Este modelo comparte algunas características con otros mencionados anteriormente, como el criollo-pendejo y el cholo-chicha.

Europeo-Gringo. En líneas generales es un estereotipo que agrupa a los extranjeros y sus descendientes, en algunas oportunidades confundidas o relacionadas con los pitucos, criollos y a veces con los mestizos. Es un grupo que surgió como resultado de la migración europea de fines del siglo XIX e inicios del XX, a pesar que el flujo ha disminuido siempre existen europeos y ciudadanos de Estados Unidos que deciden radicar en nuestro país. Este modelo de identificación tiene un fuerte vínculo con el ámbito profesional y empresarial, a veces sin merecerlo, suelen recibir una buena consideración y estatus.

Asiático-Chino. Otro modelo de identificación o estereotipo cultural es el de los asiáticos, mayoritariamente chinos; producto de su llegada en la segunda mitad del siglo XIX y principios del XX, fueron explotados en las haciendas arroceras, $y$ entendidos de manera simplificada $o$ agrupados por error con la comunidad Japonesa, Coreana, etc. Al igual que los europeos se constituyen en gran parte por los descendientes de las primeras comunidades. Suelen estar asociados al mundo comercial, en especial al negocio culinario y de abarrotes. Vistos como gente honrada, trabajadora y de confianza, la imagen de este modelo fue utilizada en la campaña de Fujimori del año 1990 lo que le dio bastante éxito y popularidad.

Selvático-Charapa.-La imagen de lo amazónico no tiene todavía una gran exploración científica, ni una fuerte explotación del marketing, la publicidad y los medios. En los últimos años ha crecido la oferta turística y musical asociada al modelo de identificación selvático. Una de las causas de su popularización se asocia al crecimiento de la cumbia, con un estilo propio y en especial con la puesta en valor de la música de "Juaneco y su Combo" realizada por bandas como "Bareto".

Podemos plantear dos modelos de identificación: el primer estereotipo es el charapa, hombre de la selva urbanizado, alegre, colorido, divertido y ligado a un fuerte erotismo y sexualidad. Representado en programas cómicos o en alguna novela ambientada en Lima como un personaje pintoresco. En artes plásticas habrían dos representaciones de este mundo exótico, colorido, erótico y sexual: las pinturas de los artistas "Lucuma” y Bendayán. En televisión hubo una serie llamada "Yuru, la princesa de 
la selva" que pretendió haber representado el mundo de lo natural, lo místico y lo mágico.

El segundo modelo son las comunidades más tradicionales y alejadas que viven en medio de la selva rodeadas de la naturaleza, con fuertes creencias mágicas; son un conjunto de culturas menos afectadas por el choque con la civilización occidental, algunas utilizan ventajas de la tecnología como la telefonía móvil o Internet para negociar y atraer turistas, mostrando su estilo de vida más natural, altamente atractivo para los extranjeros. Sus lenguajes originarios se mantienen vivos, existen grupos que todavía viven de la caza y de la pesca, comunidades tranquilas hasta que son atropelladas por el gobierno o las corporaciones nacionales y extranjeras dedicadas a la extracción de recursos naturales minerales y petroleros. A veces estas comunidades reaccionan con violencia para exigir sus derechos y buscan el reconocimiento a través de las reivindicaciones sociales.

Estos modelos de identificación cultural son solo una referencia, pues en la realidad son mucho más complejos y desbordan los límites del estereotipo, la teoría y el prejuicio porque buena parte de ellos pasan de los campos simbólicos tradicionales a los modernos, a los postmodernos, pasando por los espacios intermedios y sus difusos contornos (interculturales o transculturales), relacionados a las "Nuevas poéticas del sujeto" descritas por Portocarrero, y Komadina (2001) en su trabajo Nuevos modelos de identidad en la sociedad peruana (hacia una cartografia de los sentidos comunes emergentes).

Portocarrero trata “...de identificar las - tres- ideologías del sujeto, es decir, los discursos que establecen lo que la sociedad desea de sus miembros, lo que ellos tendrían que internalizar como metas y anhelos para ser reconocidos y valorados por el Gran Otro, por la cultura hegemónica y, por tanto, por casi todos los demás "otros" (Portocarrero, y Komadina, 2001). Los cuales son denominados: el militante, el exitista y quien busca su leyenda personal

El militante que perdió fuerza en los ochenta, es quien da su vida por la causa, pero también podría ser por el grupo, la familia, el barrio o la comunidad. Es quien se entrega totalmente, Portocarrero lo relaciona estrechamente al partidario político de orientación de izquierda, que cree en el líder carismático y en el proyecto de futuro, podría verse como un emigrante progresista.

El elitista es quien busca el éxito profesional y material, que ha ganado vigencia con las políticas neoliberales introducidas desde los noventa por el gobierno fujimorista, expuesto en los libros y discursos de Miguel Ángel Cornejo. Es aquel que trabaja para acumular bienes y lograr un gran poder adquisitivo, compensa su esfuerzo consumiendo todo lo que el dinero le permite incluyendo compañía y sexo. Aquí se mezcla el individualismo moderno, la idea de progreso y el hiperconsumo hedonista.

El modelo de búsqueda de la Leyenda personal está relacionado con la "Literatura de Autoayuda" de Coelho (1988) y con la llamada "educación en libertad" del Colegio los Reyes Rojos de Barranco fundado por Carvallo, cuya educación consiste en el descubrirse a sí mismo, encontrar las habilidades propias y desarrollarlas, es la revaloración postmoderna del "Conócete a ti mismo" que trasmitía Sócrates.

Este modelo de identidad es una valoración más subjetiva y espiritual con tintes de creencias en el destino, en los tiempos internos y circulares combinados con una concepción universal de que todo está interconectado. A la vez tiene vínculos con la tradición y el postmodernismo, principalmente.

Para terminar este punto compartimos la siguiente idea: "Una televisión de señal abierta,- y en general todos los medios de comunicación incluido el Internetculturalmente democrática, debería ser más balanceada, diversa e inclusiva, para convertirse en la arena de la que emerjan las luchas simbólicas que el país vive" (Protzel, 2009). Pero sabemos que los intereses comerciales son los que rigen, definen y determinan el uso y abuso de los modelos de identificación.

Además consideramos que es importante acotar que los modelos o estereotipos son muchas veces captados con un matiz racista que se confunde con lo cultural. Para evitar este problema reiteramos que estos modelos de identificación expuestos son referenciales y flexibles con múltiples intersecciones, pues conviven en diferentes espacios como los colegios, universidades centros de trabajo, etc., y son deformados por los medios de comunicación, los programas de televisión y la publicidad que refuerzan aspectos caricaturescos excluyentes.

\section{Diversidad como política cultural:}

Como hemos mencionado, la marca y la imagen Perú se ha vuelto muy apreciada, destacando la diversidad natural y cultural, que debe ser vista como diferencia comparativa y aprovechada para ser una diferencia competitiva. Discursos como el del exministro del Medio Ambiente, Antonio Brack, que le da un valor ecológico con potencial agroindustrial y de exportación a nuestra diversidad de productos orgánicos propios de nuestra diversidad climática; es el mismo discurso que sirvió como base para la difusión de la imagen del Perú por el ministerio de Turismo y comercio exterior promovido en su momento por la ex ministra Mercedes Araoz, quien apoyó el boom de la gastronomía peruana, emprendida por la nueva generación de Chefs como el innovador Gastón Acurio quien ha sabido fusionar la técnica y la estética de la alta cocina con la diversidad de comidas típicas, productos oriundos y sabores que son consecuencia de las fusiones culturales expresadas en la comida peruana, que podemos considerar una rica fuente y metáfora de nuestra cultura heredera de múltiples tradiciones y combinaciones culturales que continúan vivas en el pleno proceso de transformaciones.

Así el gobierno y todos en general debemos ser los artífices de la renovación y difusión de una política de la diversidad y la fusión que sea el laboratorio, bajo nuestras propias teorías, de una nueva sociedad donde convivan, 
compartan, se respeten y se relacionen una pluralidad de culturas de manera conjunta.

Un instrumento importante es un uso inteligente de los medios de comunicación para mostrar y reforzar la valoración por lo peruano y su variada riqueza tanto a nivel nacional como a nivel internacional, traspasando las barreras del markting para evitar reducir el comercio.

\section{¿Sabe con quién está hablando?, Herencia colonial, autoritarismo y racismo:}

No podemos eludir las dificultades o problemas, que podemos ver como oportunidades, surgidos de nuestros procesos históricos y sociales. Un ejemplo de paradigma es el racismo sutil y persistente en nuestra sociedad, por el cual pasamos de una supuesta democracia donde todos somos iguales ante la ley al mundo autoritario, colonial y gamonal, esa herencia de la que habla Cotler (1992), que nadie puede negar y que ha sido fuente de polémicas con la publicación del trabajo de Bruce (2012) Porque nos hemos Choleado tanto al referirse a los mecanismos del racismo en el Perú.

Lo más tragicómico es que todos nos discriminamos, todos nos choleamos, le decimos serrano, chino, negro, blanco, indio y demás a los otros, con base racial, étnica y cultural, en un país de mestizajes, quien como se dice: "El que no tiene de inga tiene de mandinga". Pero este es un recurso de diferenciación para hacer uso del poder que podemos manejar, como algunos porteros o vigilantes lo hacen cuando pueden.

Un ejemplo de un código de acceso al mundo tradicional, colonial y jerárquico donde podemos imponer nuestro pequeño poder es la frase explicada por Da Matta (2002) en el texto llamado Carnavales, Malandros y Héroes. Hacia una sociología del dilema brasileño. Trabajado en su cuarto capítulo intitulado ¿Sabe con quién está hablando? Que es una forma de eludir el sistema legal moderno de individuos para pasar a la personalización diferenciada y jerarquizada colonial.

El rito descrito por Da Matta (2002) es el revelamiento de un orden aparentemente oculto, una tradición propia de Brasil, pero también presente en el Perú y Latinoamérica principalmente, que surge para determinar un orden conservador y jerárquico de personas, que ocupan un lugar específico, en una sociedad donde se establece un dominante y un dominado. Este rito responde frente a situaciones de conflicto o crisis en una sociedad superficialmente igualitaria y moderna donde todos los individuos son anónimos y se rigen por las leyes y el mercado que establece los mecanismos de regulación; sin embargo la subsistencia de una herencia jerarquizada invalida estos mecanismos y se recurre al rito del "¿Sabe con quién está hablando?" para colocar a los individuos como personas reconocidas en roles desiguales, para solucionar el inconveniente haciendo caso omiso al mundo moderno que, finalmente, se percibe como una capa que esconde relaciones sociales complejas producto de procesos históricos que combinan elementos propios de una cultura personalista "premoderna" con otra impuesta que es individualista $\mathrm{y}$, cuyos órdenes constantemente entran en conflicto.

\section{Conclusiones}

Finalmente todos estos grupos interactúan en los diferentes campos simbólicos y que las estructuras o sistemas sociales, jurídicos y políticos no son lo suficientemente flexibles para integrarlos de manera coherente. Por eso a manera de propuesta de integración proponemos como concepto de relación, pertenencia, definición por comprensión del conjunto Perú, peruanos o peruanidad a la identidad ciudadana, que constituya la interconexión social y política, el conjunto universal que aglomere a las otras culturas. Para lograr esto, el Estado, los grupos políticos y sociales deben establecer una política de interconexiones sociales para fortalecer la identificación cultural difundiendo la diversidad cultural como valor socio-nacional, en especial aquellos que compartimos. Para ello el Estado y el gobierno peruano deben conocer y ser configurado por todas las culturas e interrelaciones con ellas, posibilitando la mayor participación en las instituciones y que estas se acerquen $\mathrm{y}$ fomenten las relaciones interculturales y transculturales.

\section{Literatura citada}

Castoriadis. 1997. El Avance de la insignificancia. Recuperado de: https://es.scribd.com/doc/137997499/ Castoriadis-Cornelius-E1-Avance-De-LaInsignificancia-pdf

Coelho. 1988. El alquimista. La búsqueda de la leyenda personal. Recuperado de: http://palabrasylogos. odiseus.org/2013/05/26/235/

Cotler, J. 1992. Descomposición política y autoritarismo en el Perú. Revista del Centro de Estudios Constitucionales. 15: 33-52. Disponible en: file://C:/ Users/of\%20Investig/Downloads/Dialnet-Descomposi cionPoliticaYAutoritarismoEnElPeru-1051304.pdf

Da Matta, R. 2002. Carnavales, Malandros y Héroes. Hacia una sociología del dilema brasileño. FCE. México.

Bruce, J. 2012. El racismo en el Perú está en el aire. Entrevista. La mula I Redacción mulera . Publicado: 2012-02-17. Disponible en: https://redaccion.lamula. pe/2012/02/17/jorge-bruce-el-racismo-en-el-peruesta-en-el-aire/admin/

Maffesoli, M. 2007. En El Crisol De Las Apariencias. Mexico, Siglo XXI. Pág. 237.

Mujica, J. s.f. Estrategias locales de acceso a la telefonía móvil. Funciones y estructuras del mercado informal en un espacio de bajos recursos. Recuperado de: http:// dirsi.net/files/Mujica.pdf

Portocarrero, G. y Komadina, J. 2001. Modelos De Identidad Y Sentidos De Pertenencia En Perú Y Bolivia. Lima, IEP. Recuperado de: https://iep.org.pe/ fondo-editorial/tienda-virtual/modelos-de-identidad- 
y-sentidos-de-pertenencia-en-peru-y-bolivia/

Protzel, J. 2009. Espacio privado y espacio público en su deriva tecnológica: notassobre la construcción histórica de la Subjetividad. Contratexto.Universidad de Lima -- No. 17, pp: 137-159. Disponible en: file:///C:/Users/of\%20Investig/Downloads/ PAREDES RODRIGUEZ CONSTANZA TRIBUS URBANAS.pdf

Sartori, G. 1988. Teoria de la democracia. Tomo uno. Madrid, España, Alianza Editorial. Recuperado de: https://www.marcialpons.es/libros/teoria-de-lademocracia-1/9788420625669/

Vargas, A. s.f. Identidad y sentido de pertenencia. una mirada desde la cotidianeidad. Recuperado de: http://132.248.35.1/cultura/ponencias/1 cultDesa/ CDIDE02.htm 